\title{
Risk Switch and Momentum Strategy: How Do Optimized Portfolios Perform?
}

\author{
Ulrich R. Deinwallner, $\mathrm{PhD}^{*}$
}

PhD Management and Finance, Walden University, USA Volmerswerther Str. 384; 40221 Düsseldorf; Germany

DOI: $10.36348 /$ sjef.2020.v04i03.005 $\quad$ | Received: 07.03.2020 | Accepted: 21.03.2020 | Published: 27.03 .2020

*Corresponding author: Dr. Ulrich R. Deinwallner

\section{Abstract}

Optimization is a common method to improve the performance of a stock portfolio. However, it was unclear what performance to expect for a risk switch (RS) strategy and a moving average adjusted long only momentum (MA MOM) strategy as a benchmark. The research question was: how does a RS strategy with optimized portfolios perform in comparison to equal weights and to a benchmark for U.S. stocks? In this study, high Betas during winter and low Idiosyncratic Volatility during summer were computed to construct the RS portfolios. The computations required to consider a capital asset price model, Sharpe ratios, Efficient Frontier, F-test next to others. I find in this study that an optimization was only most profitable for a RS strategy, with a percentile range of $r_{R S}[0.56 ; 2.52 \%$ per month] during 2009 until 2019, and for Dow Jones Industrial Average stock market data. The findings are relevant for investors and portfolio managers who optimize portfolios and are interested to apply a RS or a MA MOM strategy.

Keywords: Risk Switch Strategy, Momentum Strategy, MA MOM, Portfolio Management, Optimization, Efficient Frontier, Beta, Idiosyncratic Volatility, CAPM.

Copyright @ 2020: This is an open-access article distributed under the terms of the Creative Commons Attribution license which permits unrestricted use, distribution, and reproduction in any medium for non-commercial use (NonCommercial, or CC-BY-NC) provided the original author and source are credited.

\section{INTRODUCTION \\ Low Risk}

According to researchers, excess return can be achieved when following a low risk strategy. Asness, Frazzini, and Pedersen [1] found that investors do not appreciate leverage for their investment and rather prefer high risk stocks. Baker, Bradley, and Wurgler [2] also presented findings to low-risk stock strategies in their study. Baker et al. found that low risk stocks are often underweighted in portfolios, since other investments can replicate the movement of a market's benchmark more efficiently. Chow, Hsu, Kuo, and Li [3] argued that low-risk stocks can offer the investor higher returns because of a lower volatility compared to other investments. A lower volatility of stocks means in this case that the market factor exposure is not as high as for large Beta (B) stocks. The lower volatility has the effect of a better risk and return relation in comparison to other investments [3]. According to Fong and Koh [4], low B stocks performed better than high B stocks, and compared to stock/bond portfolios. Walkshäusl [5] saw the value of low-risk stocks for long-term investments as practical because the firms that exhibit a lower volatility also seemed to possess mostly a higher quality. Therefore, low-risk stocks can generate abnormal excess returns for investors as alternative to stock/bond portfolio asset allocation strategies.

\section{Seasonality}

When discussing low risk, then seasonality effect should also be mentioned. Fong and Koh [4] indicated and Jacobsen and Visaltanachoti [6] confirmed that investors prefer to buy stocks during the winter months and invest in bonds during the summer months, where the time periods were for summer months (May-October) and for winter months (November-April). However, a switch between low risk (summer) and high B stocks (winter) can be more profitable in comparison to a stock / bond strategy [7]. Hong and $\mathrm{Yu}$ [8] saw a reason for these findings in the cause of a seasonality effect for the market's performance by vacation-behavior. Kamstra, Kramer and Levi [9] proclaimed that risk aversion investors caused in the summer months a seasonal affected disorder, while Cao and Wei [10] made a connection with temperature changes. All of these researchers saw behavioral aspects as an explanation for seasonality as a market-wide phenomenon that impacts stock returns. In consequence, investors should follow a risk switch (RS) strategy to capitalize from a seasonality effect. 


\section{Momentum Strategy}

This brings up the question for alternative investment strategies as a benchmark for investors. Several studies presented findings to the momentum effect in the capital markets [11-13]. Jegadeesh and Titman [13] recommended benefiting from the momentum effect, by buying recent winner stocks and selling recent loser stocks. It was Foltice and Langer [14], who suggested modifying the momentum strategy and investors with small portfolios should follow a long only momentum (MOM) strategy, where only recent winner stocks are bought for an investment portfolio [14]. It is to mention that the MOM strategy builds upon the findings of Levy in 1967. Jegadeesh and Titman [13] stated that there are different strategies of how a security portfolio can be formed for the momentum strategy. For example, a portfolio can be differently constructed through $(\mathrm{h}=$ return period) and $(\mathrm{k}=$ holding period) combinations of $[\mathrm{h}: \mathrm{k}]$ or [3:3], [6:6], [9:9], or [12:12] trading strategies [13]. In case of a [6:12] combination, the returns of the past 6 months are considered for the selection of the top and bottom $10 \%$ winner and loser stocks, and then these stocks are held for the next 12 months and so forth [13]. Deinwallner [15] tested the application of a moving average adjusted (MA) for the MOM strategy for Dow Jones Industrial Average (DJIA) data. For the MA MOM strategy and for an investment above $\$ 5,000$, a quarterly trading frequency for overlapping portfolios should be considered (except for values above \$1 Mill.). For a yearly MA MOM strategy, the portfolios should be formed according to the $10 \%-20 \%$ highest returns of the past six months, and then the investments should be held for one year or rebalancing after one year [15]. The MA indicator, to identify the Bull and the Bear market phases of the underlying stock market index, was a simple moving average (SMA) with the settings SMA(6 vs. 36).

\section{Portfolio Optimization}

The risk and reward relation of an investment strategy can be improved through the optimization of the portfolios. The mean variance approach to optimize portfolios was first introduced by Markowitz [16]. Meanwhile the portfolio allocation is well examined in the finance literature. Recent work has been published by Bernard and Vanduffel [17], Pourbabaee, Minsuk, and Pirvu [18], Bernard, Dries, and Vanduffel [19], Kondor, Papp, and Caccioli [20], Landsman, Udi, and Shushi [21], and Maheshwari and Pirvu [22] which all addressed the issue of mean variance optimization for portfolios, while Lobo, Fazel, and Boyd [23] had a special focus on the optimized portfolio costs. Maheshwari and Pirvu [22] mention a time inconsistency for the optimized portfolios that occurred if the risk constrains were dynamically updated and saw correlation constrains as causal. Kondor, Papp, and Caccioli [20] presented an analysis to variance minimization portfolios that considered no short-selling solutions. Jorion [24] added here that portfolios can generally be constructed with short-sales, liquidity, transaction cost, and turnover constrains, and saw the mean-variance optimization as a very flexible instrument to use. In Jorion's [24] study, findings were presented to optimized portfolio constructions in practice, displaying the portfolio correlations and the efficient frontiers. All researchers presented a statistic framework in their studies and made a contribution to the investigation of portfolio optimization.

The current situation is that much has been publish to portfolio optimization and RS strategies. However, a combination of both issues and especially in regard of the MA MOM strategy seemed underrepresented in the scholarly literature. The question occurred, if optimization is always the best choice when applying an investment strategy.

The general problem is that it was unclear what return differences to expect for an optimized RS strategy and MA MOM strategy. Therefore, the specific problem is to test how a RS strategy and a MA MOM strategy perform under optimizing or none optimizing, and no short-sales constrains. The study can be relevant for investors and portfolio managers to learn more about the risk, return and effort of applying a RS and MA MOM strategy, when conducting optimized portfolios.

The purpose of this quasi experimental, comparative study is to test a RS strategy and a MA MOM strategy in comparison to optimized weights (OW) and equally weighted (EW) portfolios without short-sell constrains (independent variable) to investigate the excess return performance (dependent variable) for DJIA U.S. stock data.

\section{Research Question}

This study is guided by one research question (RQ): How does a RS strategy with optimized portfolios perform in comparison to equal weights and to a benchmark for U.S. stocks?

\section{To answer the research question two Hypotheses $(H)$ are relevant to investigate}

$H_{0} 1$ : if RS strategy portfolios are constructed and compared for optimized portfolios, by maximizing Sharpe ratios with no short-sales constrains, and for EWportfolios, then the optimized portfolio excess returns cannot outperform the other variation.

$H_{1} 1$ : if RS strategy portfolios are constructed and compared for optimized portfolios, by maximizing Sharpe ratios with no short-sales constrains, and for EW portfolios, then the optimized portfolio excess returns can outperform the other variation.

$H_{0} 2$ : if RS and MA MOM strategies with optimized portfolios for maximized Sharpe ratios with no short-sales constrains are compared to a stock 
market index buy and hold strategy, then the optimized MA MOM portfolios cannot outperform the other variations.

$H_{1}$ 2: if RS and MA MOM strategies with optimized portfolios for maximized Sharpe ratios with no short-sales constrains are compared to a stock market index buy and hold strategy, then the optimized MA MOM portfolios can outperform the other variations

\section{Summary}

For the study, DJIA U.S. stock market data and Kenneth French data was considered. From the data, RS strategy and MA MOM portfolios were constructed during a time period of 2009 until 2019. The study can contribute to the literature of seasonality, risk strategies and momentum strategies in the scholarly body of literature. The study differs from other studies, since two relevant investment strategies were further investigated in regard of portfolio optimization. In the method section, I display the considered equations for the computations, for example the Capital Asset Price Model (CAPM), Sharpe Ratios, Transaction costs and so forth. In the empirical section, I investigate first H1 and compare optimized RS strategy portfolios to EW portfolios. Then, I investigate $\mathrm{H} 2$ and compare the optimized MA MOM strategy to an EW MA MOM strategy. I compute a $F$-Test and present a line chart to determine heuristically which strategy is most profitable to invest in. Finally, I present an Efficient Frontier for one RS portfolio and conduct estimates through multivariate standard normal distributed values, to investigate the reliability of portfolio optimization. The findings are relevant for investors and portfolio managers who optimize their portfolios and are interested in applying a RS and a MA MOM strategy.

\section{DATA AND METHODOLOGY}

For the analysis, I use dividend adjusted daily closing prices from the DJIA stocks and index over the time period of January 02, 2009 until December 31, 2019 (11 years). I also use the risk factor data that is provided by Kenneth French's website to compute a CAPM, published on the website https://mba.tuck.dartmouth.edu/pages/faculty/ken.frenc h/data_library.html [18]. I collect the DJIA data from the internet source Yahoo!Finance [25].

I make a limitation for the results of this study in regard of U.S. security portfolios and to the data of the DJIA and the data of Kenneth French (i.e., T-Bills). This means that size effects might not be present in the selected data since the DJIA only represents large cap stocks. For the study, I will test a practical approach of portfolio optimization of the DJIA data.

Bouman and Jacobsen's [6] stressed that no larger findings were reported for risk stock strategies between investigated sectors in their study, because the sectors and the years were limited. Jacobsen and Visaltanachoti [6] vestigated a time-period of more than 80 years and a large number of sectors and partitioning to find seasonality effects for U.S. security markets. My assumptions are that seasonality and risk effects are also present for the DJIA data in a much shorter time-period. I will compute B and IV for the chosen RS strategy in this study by computing a CAPM. I will compare different portfolio constructions of the RS strategies and of the MA MOM strategy to answer the research question and to determine the performance for an investment in these strategies. This can be relevant for investors and portfolio managers who decide to apply one of these two strategies for their investments. Methodology

The CAPM can help to compute the systematic risk and the unsystematic risk in this study [2]. Through the computations of the CAPM, the risk factors for RS strategy are obtained and are further elaborated in the subsequent analysis. The equation for the CAPM is [7]:

$$
r_{i}=R_{F}+\beta_{i}\left(R_{m}-R_{F}\right)+\varepsilon_{i}
$$

Where

$\left(R_{M^{-}} R_{F}\right)=$ excess market return

$R_{F}=$ risk free rate $\left(R_{F}\right)$

$r_{i}=$ excess return of portfolio and $i=1, \ldots, k$

$\beta_{i}=\mathrm{B}$ or the sensitivity of the security $i=1, \ldots, k ; k=$ the number of variables

$\varepsilon_{i}=$ error-term

While,

$I V_{i}=\sqrt{\operatorname{var}}\left(\hat{\varepsilon}_{i}\right)$ or the standard deviation (STD) of the error-term.

Through the Sharpe ratio, the investor can assesses the average excess return value per unit of the underlying systematic risk. The Sharpe ratio allows an evaluation of asset's or a portfolio's performance associated to the underlying risk. The larger the Sharpe ratio value is, the more attractive an investment is because of the risk and return relation.

$$
S R_{i}=\frac{\left(r_{i}-R_{f}\right)}{\sigma_{i}}
$$

Where, $r=$ stock or portfolio return, $R_{f}=$ the risk free rate, $\sigma=\mathrm{STD}$, of the stock or portfolio $i$ $=1, \ldots, k ; k=$ the number of variables; $S R=$ Sharpe Ration.

The significance is computed with a $t$-test through the following equation:

$$
t=\frac{X_{1}-X_{2}}{\sqrt{\frac{\sigma_{1}}{n_{1}}+\frac{\sigma_{2}}{n_{2}}}}
$$


Where, $\mathrm{X}=$ the return, $\sigma=$ the STD, and $n=$ the number of cases [26].

The MA is an $n$-lagged indicator that is based on past asset prices. From the indicator and for financial decision making, two main trading signals can be gained: (a) price crossover signals and (b) double cross over signals [27, 28]. The equation for a simple moving average (SMA) is:

$$
S M A=\frac{P_{M}+P_{M-1}+\ldots+P_{M-(n-1)}}{n}
$$

Where, $P_{M}=$ the price of the asset $M$; and $n=$ the number of days considered for the closing

The transaction costs are critical to apply for then analysis of portfolios. Three kinds of transaction costs can occur for a trade in the portfolios. (a) Commission of $\$ 10$ per trade, which represents for an investment of $\$ 5,000=0.2 \%$ in this study. (b) The $\mathrm{Bid} /$ Ask spread, which is for market capitalization corporations $>\$ 11,365.8 \mathrm{~m}=0.497 \%$ spread. This is the case for DJIA data (c) And, the Securities and Exchange Commission (SEC) fee, which had prior to December 29, 2001 the value of $0.003333 \%$ for every sale of stock [14].

\section{The equation to compute the transaction costs is:}

$$
o=(2 * c)+(2 * 0.5 s)+f
$$

Where, $c=$ sales commission of $0.2 \%$ per trade; $s=$ the spread of $0.497 \%$ per trade; $f=$ the SEC sales fee of $0.003333 \%$; while $o=$ is the total costs implied for the constructed portfolios [14]

\section{RESEARCH DESIGN}

For the research design, I will construct portfolios containing a cut-off level of $20 \%$ of the DJIA stocks, which means 6 stocks per portfolio which is congruent to Deinwallner [15] recommendations. The time-periods for the RS strategy to select for the seasonality are for summer months (May-October) and for winter months (November-April) [6]. The two risk parameters that I will test in regard of the RS strategy are during the summer month's low IV values and during the winter month's high B values [7, 4]. Further, I will test $\mathrm{H} 1$ to investigate the difference between EW and OW for the RS strategy portfolios with no shortsales constrains in comparison. Then, I will test $\mathrm{H} 2$ to investigate the performance of a RS strategy with OW for the portfolios and with no short-sales constrains in comparison to two different benchmarks. The two benchmarks will be: (a) a MA MOM strategy and (b) a buy and hold strategy of the DJIA index, to answer the research question.

Further I will conduct an analysis of portfolio optimization through estimated values. I will construct an efficient frontier from the RS strategy stock selections. Then, I will estimate the optimized portfolio with estimated values of a multivariate standardized normal distribution as performed by Jorion [24]. The values will be oriented at the optimized RS strategy portfolio values and their stock excess return means, covariance-variance matrix and STD. From this, I can compute estimated portfolio excess return means and STD. These values will be populated under the efficient frontier curve to determine how precise the estimations can be. Also, I will compute a linear Capital Market Line (CML) to display the market portfolio, by multiplying the portfolio STD to the optimized Sharpe Ratio of the RS strategy and by adding this value to the risk free rate.

Because private investors tend to lose capital in the financial markets, this study is for educational reasons, does not represent investment advice, and investors should conduct their own research before investing their capital [29]. The threads to external validity are that the analysis of DJIA data might not be representative for all U.S. stocks or for future stock market developments. The threats for internal validity are that the seasonality was assumed and might not be as relevant as assumed. Also the RS strategies are oriented at the lowest and highest risk values and might not exhibit the optimal returns that can be achieved with risk oriented investment strategies. Also, the MA MOM strategy was only applied for a yearly trading frequency strategy. The most profitable method of overlapping portfolios was not considered and can lead to different results [15]. This means that deviations could occur for the results in comparison to other findings. Deviations for the results can also come from the aspect that maybe longer time periods would be required for the results to be meaningful. Further, Jorion [24] mentioned that there is a tradeoff between the precision of the optimal portfolio weights and the validity of out of sample periods, which my test of the efficient frontier and the estimates also could indicate.

\section{EMPIRICAL FINDINGS}

Analysis and Discussion of $\mathrm{H1}$

For the analysis of H1, I collected DJIA and the Kenneth French data. I determined the winter and summer months for the stock data tables. Then, I computed the excess returns from the stock returns by subtracting the risk free rate. I computed the B and the IV from the DJIA and the Kenneth French data. I selected one until six stocks for each season, for winter the one until six highest $\mathrm{B}$ values and for summer the one until six lowest IVs stocks, and populated the portfolios (see Table A1 in the appendix). For the selection of the stocks for the portfolios, I considered a six months formation period. From this past formation period, I computed a covariance-variance matrix $(\Sigma)$, and from the covariance-variance matrix and the portfolio weights vectors ( $\omega^{T} \Sigma \omega$ ), I could compute the portfolio variance and the STD. I optimized the 
portfolio weights from this data by maximizing the Sharpe ratios and selecting no short-sales constrains. Then, I computed a covariance- variance matrix for the sample data and determined the portfolio excess returns, STD and Sharpe ratio values. To these excess returns of the portfolios, I also applied the transaction costs, which equaled to a value of $(-0.012303 \%)$ according to Equation 5 for each trade. I held the stocks for six months in the portfolios before I rebalanced the portfolios because of the next seasonality switch. In Figure 1, I omitted the Sharpe ratios for the last two months in 2019, since the STD for two months was lower in comparison to the other 6 months STD, which I treated as an outlier for the comparison.

From Figure 1, I can find that a RS strategy was, except from 2015 to 2016, always profitable to trade. Also, I could find that the RS strategy with optimized portfolios seemed, but was not significantly different, with $\left(r_{O W}=1.67 \%\right.$ average monthly excess return) more profitable compared to an EW portfolio strategy with $\left(r_{E W}=1.29 \%\right.$ average monthly excess return), while the returns were transactions cost adjusted. Average excess returns ranged per month according to the quintiles for $\mathrm{OW}$ portfolios between $[.56 \% ; 2.52 \%]$ while the EW portfolio ranged between $[0.68 \% ; 2.05 \%]$. The stocks, excess returns, and weights for the RS portfolios can be found in the appendix in Table A1. I could not reject the Null Hypothesis 1 at a $1 \%$ alpha level, because the optimized portfolios excess returns were not on average more profitable compared to EW portfolio excess return, with a $t$-test with $t(22)=0.084, p=.4681$ caused through a high portfolio STD.

Table-1

\begin{tabular}{|l|r|r|r|}
\hline \multicolumn{2}{|l|}{ RS Strategy Statistics 2009-2019 } \\
\hline $\mathrm{N}$ & Portfolios & \multicolumn{1}{c|}{$\mathrm{r}_{\mathrm{EW}}$} & \multicolumn{1}{c|}{$\mathrm{r}_{\mathrm{OW}}$} \\
\hline \multicolumn{2}{|l|}{} & & 23 \\
\hline \multicolumn{2}{|l|}{} & 1.3196 & 1.8809 \\
\hline Median & 1.26 & 1.37 \\
\hline Std. Deviation & 5.46 & 4.78 \\
\hline Sharpe Ratio & 0.24 & 0.39 \\
\hline Range & 4.96 & 11.08 \\
\hline Minimum & -1.05 & -.75 \\
\hline Maximum & 3.91 & 10.33 \\
\hline Percentiles & 25 & .68 & .56 \\
\cline { 2 - 4 } & 50 & 1.26 & 1.37 \\
\cline { 2 - 4 } & 75 & 2.13 & 2.52 \\
\hline
\end{tabular}

Note. All portfolio values are excess returns, transaction cost adjusted, per month, and in (\%).

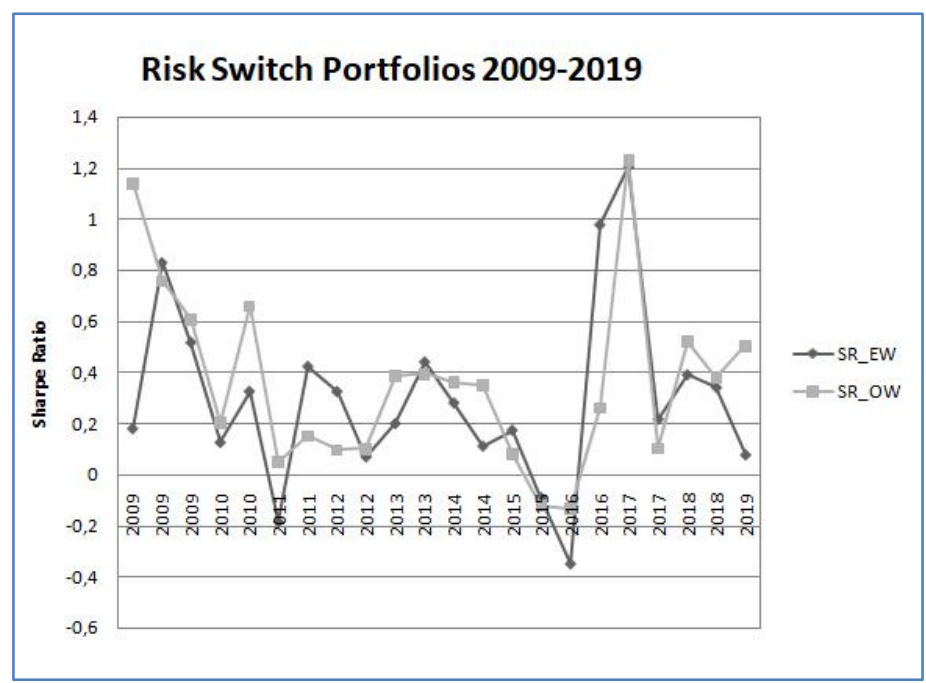

Fig-1: The figure displays monthly average Sharpe ratios (SR) of the constructed RS portfolios. The RS portfolios consider EW and OW

\section{Analysis and Discussion of $\mathrm{H2}$}

For the analysis of $\mathrm{H} 2$, I determined the excess returns for the DJIA stocks. Then, I constructed portfolios with the MA MOM strategy. For the MA MOM strategy, I applied the MA, meaning the SMA(6 vs. 36), to the DJIA data and found that during 2009-01 until 2010-03 and during 2010-06 "Sell" signals occurred. This means that I did not consider this DJIA stock data in the construction of the MA MOM portfolios. I used a 6 months formation period for the MA MOM strategy, which means that I considered the highest returns, and held six selected stocks (20\% 
cutoff), one year in the portfolios. Through this, I obtained $n=11$ portfolios (see in the Appendix Table A2). I computed the frequency statistic and applied a $F$-Test in comparison to the RS strategy with OW, the MA MOM strategy with EW and OW, and the DJIA data.

The excess returns of the MA MOM EW portfolios do not significantly differ from the $\mathrm{OW}$ portfolios at a $1 \%$ alpha level, according to a $t$-test with $t(10)=0.107, p=.4562$. However, EW portfolios should be preferred for the MA MOM strategy, since they cause less statistical effort and show in these small sample cases heuristically more profitable results. Therefore, the Null Hypothesis 2 could not be rejected at a $1 \%$ alpha level, because the optimized MA MOM strategy portfolio excess returns did not outperform the benchmarks returns significantly.

Table-2

\begin{tabular}{|l|r|r|r|}
\hline \multicolumn{4}{|l|}{ MA MOM Strategy Statistics 2009-2019 } \\
\hline N & Portfolios & 11 & 11 \\
\hline Mean & .5045 & -.1064 \\
\hline Median & 1.03 & .99 \\
\hline Std. Deviation & 3,69 & 3,82 \\
\hline Sharpe Ratio & 0.14 & -0.3 \\
\hline Range & 6.82 & 9.32 \\
\hline Minimum & -4.37 & -7.01 \\
\hline Maximum & 2.45 & 2.31 \\
\hline Percentiles & 25 & .15 & -.80 \\
\cline { 2 - 4 } & 50 & 1.03 & .99 \\
\cline { 2 - 4 } & 75 & 1.55 & 1.40 \\
\hline
\end{tabular}

Note. All portfolio values are excess returns, transaction cost adjusted, per month, and in (\%).

A F-test in Table 3 showed that both strategies are most profitable to trade in comparison to a simple buy and hold strategy. In other words, if the buy and hold strategy were efficient, and then in only $0.37 \%$ of the cases would the observed vales of the MA MOM strategy EW be exceeded.

Table-3

\begin{tabular}{|l|c|c|c|c|c|}
\hline \multicolumn{7}{|c|}{ F- Test Comparison of the portfolio returns, 2009-2019 } & \\
\hline & & & & F-Test (p-values) & \\
\hline Portfolio & Mean & STD & Mean/STD & RS vs. DJIA & MA MOM vs. DJIA \\
\hline DJIA Buy and Hold Strategy & 0.82 & 61.56 & 0.01 & & \\
\hline RS Strategy OW & 1.88 & 4.78 & 0.39 & 6.275 & 6.306 \\
\hline MA MOM Strategy EW & 0.51 & 3.69 & 0.14 & $(0.0031 \%)$ & $(0.37 \%)$ \\
\hline
\end{tabular}

Not. The $F$ - Test measures if the strategies differ between the performances of the portfolio excess returns. The p-values are one sided and report the proportion of how many times the values of the test was outperformed under the Null hypothesis. All portfolio values are excess returns, transaction cost adjusted, per month, and in (\%).

In Figure 2, a comparison between the investigated strategies with yearly average excess and cost adjusted returns reviled that the RS optimized strategy was heuristically most profitable, while the optimization of a MA MOM strategy was not recommendable. The finding considering the MA
MOM strategy could indicate that the optimization of portfolios cannot always be the best solution, since the optimization occurred on historical and not future data. This aspect brings up the question for estimation errors in regard of portfolio optimization, which I discuss in the next paragraph. 


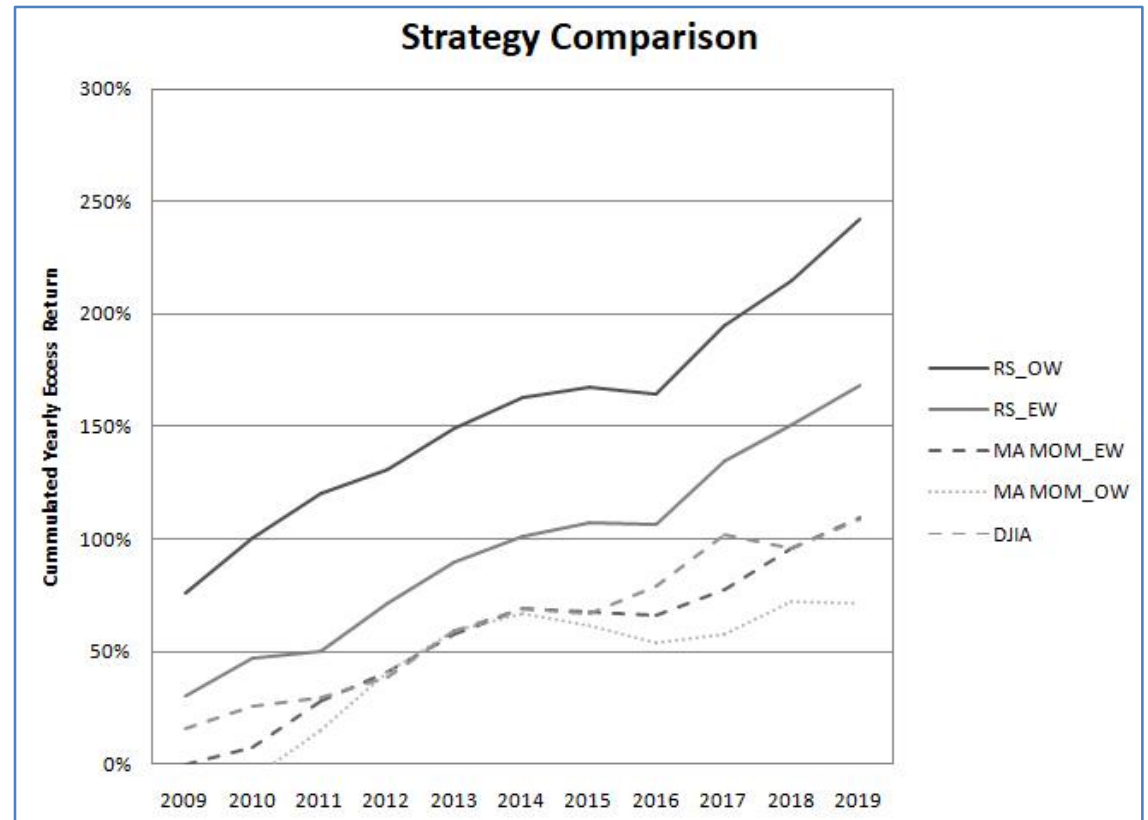

Fig-2: In the figure a comparison of the investigated strategies was conducted. The strategies data was obtained from average monthly returns and then projected $\left(\left(1+r^{\wedge}(n)\right)-1\right)$ to yearly average cost adjusted excess returns.

In Figure 3, I display the Efficient Frontier for the RS strategy portfolios during 2019-05 until 201910. The OW and the SR value deviates in Figure 3 from the Table A1 values, since not the 6 months formation phase values, but, the holding phase values of the sample were computed for this analysis. The figure shows that six DJIA stocks with excess returns and their STD were selected that distribute widely over a return and STD range. The optimal portfolio or the market portfolio is displayed at the point where the CML meets the Efficient Frontier, starting from the risk-free rate and added by the RS portfolio optimal Sharpe ratio multiplied with the RS portfolio STD. In gray, $n=20$ estimates were computed, through a multivariate standard normal distribution values as described by Jorion [24]. From these estimates, I can find and confirm that an outside of the sample tests might lead to different results, since the estimation varies frequently from the Efficient Frontier curve.

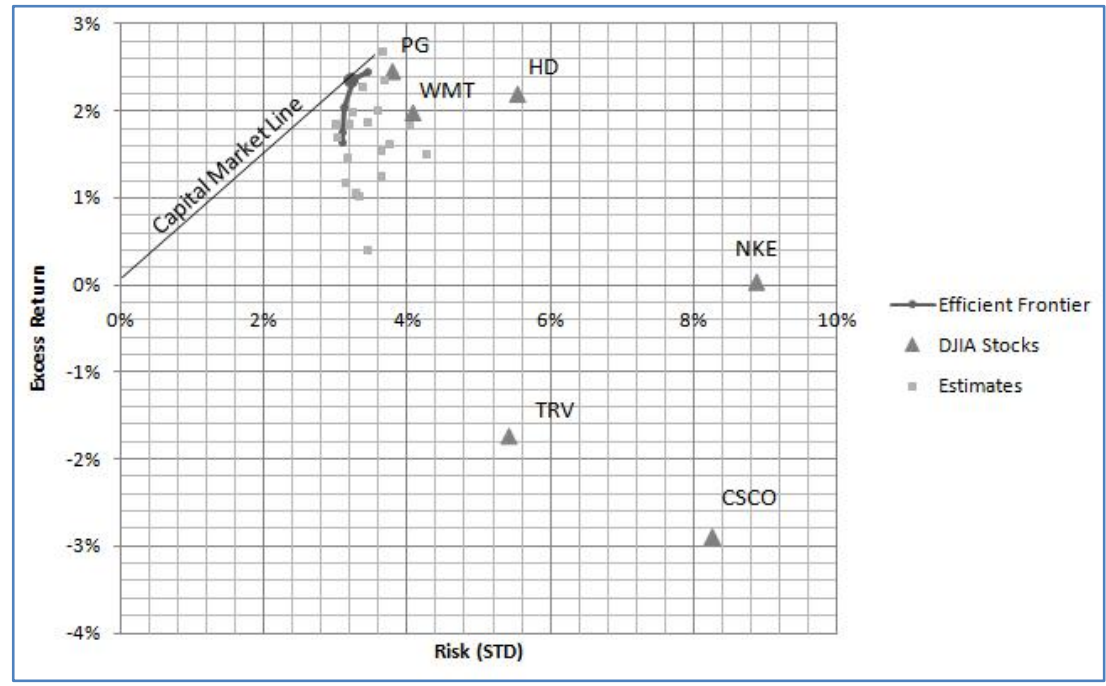

Fig-3: The figure displays an Efficient Frontier of a RS strategy during 2019-05 until 2019-10 (summer = low IV's), six DJIA stocks, $\mathrm{n}=\mathbf{2 0}$ multivariate standard normal distribution estimated values, and a CML. The CML started at the risk-free rate $\left(r_{\mathrm{RF}}=0.178\right)$, the optimal Sharpe ratio for the market portfolio was $(S R=0.72)$. In the table monthly average excess returns, transaction cost adjusted, in $(\%)$ values, and stock STD's and portfolio STD's are presented

\section{CONCLUSION}

In the study, the RQ: how does a RS strategy with optimized portfolios perform in comparison to equal weights and to a benchmark for U.S. stocks, reveled the following results. To optimize a RS strategy was most profitable, but not significantly different in comparison to EW RS strategy, with a percentile $(25 \%$, $75 \%)$ range of $r_{R S}[0.56 ; 2.52 \%$ per month]. However, the optimization was for the benchmark, a MA MOM 
strategy, not recommendable and produced heuristically the lowest returns even in comparison to a buy and hold strategy of the DJIA (see Figure 2). This raised the question, if optimization is always profitable for the construction of portfolios. Further, the optimization of portfolios can lead to different results in case of out-ofsample tests, which Figure 3 showed. Multi standard normal distribution estimates varied and confirmed the findings of Jorion [24, 30] in regard of a precision tradeoff. The issue was that optimized portfolios only consider historic past data and cannot capture exactly future risks and market developments. The findings are relevant for investors and portfolio managers who optimize their portfolios and are interested to apply a RS or a MA MOM strategy. Further research can be conducted in regard of the investigation of the MA MOM strategy and for example optimization effects.

\section{REFERENCES}

1. Asness, C. S., Frazzini, A., \& Pedersen, L. H. (2012). Leverage aversion and risk parity. Financial Analysts Journal, 68(1), 47-59.

2. Baker, M., Bradley, B., \& Wurgler, J. (2011). Benchmarks as limits to arbitrage: Understanding thelow-volatility anomaly. Financial Analysts Journal, 67(1), 40-54.

3. Chow, T. M., Hsu, J. C., Kuo, L. L., \& Li, F. (2014). A study of low volatility portfolio construction methods. Journal of Portfolio Management, $\quad 40(4), \quad$ 89-105. doi:10.3905/jpm.2014.40.4.089

4. Fong, W. M., \& Koh, T.(2015). Strategic asset allocation with low-risk stocks: A bootstrap analysis. Journal of Investment Management, 13(2), 39-58. Retrieved from https://www.joim.com/wpcontent/uploads/emember/downloads/10.pdf

5. Walkshäusl, C. (2013). The high returns to low volatility stocks are actually a premium on high quality forms. Review of Financial Economics, 22(4), 180-186.

6. Jacobsen, B., \&Visaltanachoti, N. (2009). The Halloween effect in U.S. sectors. The Financial Review, 44(3), 437-459.

7. Fiore, C. \& Saha, A. (2015). A tale of two anomalies: Higher returns of low-risk stocks and return seasonality. The Financial Review, 50, 257273.

8. Hong, H., \& Yu, J. (2009). Gone fishin': Seasonality in trading activity and asset prices. Journal of Financial Markets, 12(4), 672-702.

9. Kamstra, M. J., Kramer, L. A., \& Levi, M. D. (2003). Winter blues: A SAD stock market cycle. American Economic Review, 93(1), 324-343.

10. Cao, M., \& Wei, J. (2005) Stock market returns: A note on temperature anomaly. Journal of Banking and Finance, 29(6), 1559-1573.

11. Bornholt, G., Dou, P., \& Malin, M. (2015). Trading volume and momentum: The international evidence. Multinational Finance Journal, 19(4),
267-313.

Retrieved from http://www.efmaefm.org/oefmameetings/efma annual meetings/2014Rome/papers/EFMA2014_0049_fullpaper.pdf

12. Hung, C., \& Banerjee, A. (2014). How do momentum strategies "score" against individual investors in Taiwan, Hong Kong and Korea? Emerging Markets Review, 21, 67-81.

13. Jegadeesh, N., \& Titman, S. (1993). Return to buying winners and selling losers: Implication for stock market efficiency. Journal of Finance, 48(1), 65-91.

14. Foltice, B., \& Langer, T. (2015). Profitable momentum trading strategies for individual investors. Financial Markets and Portfolio Management, 29(2), 85-113.

15. Deinwallner, U. R. (2019). Adjusting the momentum strategy for small investors. Walden Univeristy, ProQuest Dissertations Publishing, 1171.

https://search.proquest.com/openview/0cbea0e3008 7b3c4e80f23bd180ad580

16. Markowitz, H. (1952). Portfolio selection. The Journal of Finance, 7(1), 77-91.

17. Bernard, C., \& Vanduffel, S. (2014). Meanvariance optimal portfolios in the presence of a benchmark with applications to fraud detection. European Journal of Operational Research 234: 469-80.

18. Pourbabaee, F., Minsuk K., \& Pirvu, T. A. (2016). Risk minimization and portfolio diversification. Quantitative Finance 16: 1325-32.

19. Bernard, C., Dries C., \& Vanduffel S. (2018). Optimal portfolios under a correlation constraint Quantitative Finance 18: 333-45.

20. Kondor, I., Papp, G. and Caccioli, F. (2017). Analytic solution to variance optimization with no short positions. Journal of Statistical Mechanics: Theory and Experiment 2017: 1-29. Retrieved from

https://discovery.ucl.ac.uk/id/eprint/10044428/1/Va rianceNoShortSellingJStatSecondSubmission2.pdf

21. Landsman, Z., Udi, M., and Shushi, T.(2018). A generalized measure for the optimal portfolio selection problem and its explicit solution. Risks 6: 19.

22. Maheshwari, A., \& Pirvu, T. A. (2020). Portfolio Optimization under Correlation Constraint. Risks, 8(1), 15.

23. Lobo, M. S., Fazel, M., \& Boyd, S. (2007). Portfolio optimization with linear and fixed transaction costs. Annals of Operations Research, 152(1), 341-365.

24. Jorion, P. (1992). Portfolio optimization in practice. Financial Analysts Journal, 48(1), 68-74.

25. Ren, L., \& Ren, P. (2018). Applying a combined max-min simple moving average trading strategy to market indexes. Economics, Management, \& Financial Markets, 13(2), 11-23. Retrieved from 
https://www.ceeol.com/search/article-

detail $? \mathrm{id}=676861$

26. Chang, Y., Metghalchi, M., \& Chan, C. (2006). Technical trading strategies and cross-national information linkage: The case of Taiwan stock market. Applied Financial Economics, 16(10), 731-743. doi:10.1080/09603100500426374

27. Thema, F. T., Beukes, P., Gurib-Fakim, A., \& Maaza, M. (2015). Green synthesis of Monteponite $\mathrm{CdO}$ nanoparticles by Agathosma betulina natural extract. Journal of Alloys and Compounds, 646, 1043-1048.
28. Nedeltcheva, G. N. (2015). Forecasting stock market trends. Economic Quality Control, 30(1), 21-38.

29. Abbey, B. S., \& Doukas, J., A. (2012). Is technical analysis profitable for individual currency traders? Journal of Portfolio Management, 39(1), 142-150.

30. Chin-Sheng, H., Chun-Fan, Y., Jiang-Chuan, H., \& Su-Wen, K. (2014). The practice of dividend-yield strategies in the greater China region. Asian Economicand Financial Review, 4(11), 1607. Retrieved from http://www.conscientiabeam.com/pdffiles/eco/3/aefr-2014-4(11)-1607-1621.

\section{Appendix}

Table -A 1

\begin{tabular}{|c|c|c|c|c|c|c|c|c|c|}
\hline \multicolumn{10}{|c|}{ Low (S) \& High (W) Seasonality RS Strategy Portfolios 2009-2019 } \\
\hline DJIA Stocks & 1 & 2 & 3 & 4 & 5 & 6 & Portfolio & & \\
\hline 2009-01 until 2009-04 & CAT & GS & $\mathrm{UNH}$ & INTC & WBA & $\mathrm{CSCO}$ & $\mathrm{r}$ & STD & SR \\
\hline Ave. $\mathrm{r}$ risk adj. & -5.74 & 10.33 & -3.36 & 1.78 & 5.84 & 3.93 & & & \\
\hline Equal weights & 16.67 & 16.67 & 16.67 & 16.67 & 16.67 & 16.67 & 2.13 & 11.69 & 0.18 \\
\hline Opt. weights_ns & 0.00 & 100.00 & 0.00 & 0.00 & 0.00 & 0.00 & 10.33 & 9.06 & 1.14 \\
\hline 2009-05 until 2009-10 & HD & NKE & $\mathrm{CSCO}$ & MSFT & DIS & JNJ & & & \\
\hline Ave. $r$ risk adj. & -0.72 & 3.22 & 2.56 & 5.22 & 3.50 & 2.07 & & & \\
\hline Equal weights & 16.67 & 16.67 & 16.67 & 16.67 & 16.67 & 16.67 & 2.64 & 3.18 & 0.83 \\
\hline Opt. weights_ns & 0.00 & 0.00 & 0.00 & 0.00 & 100.00 & 0.00 & 3.50 & 4.63 & 0.76 \\
\hline 2009-11 until 2010-04 & JPM & CAT & BA & GS & NKE & $\mathrm{CSCO}$ & & & \\
\hline Ave. $r$ risk adj. & 0.15 & 3.56 & 6.98 & -2.78 & 3.66 & 2.56 & & & \\
\hline Equal weights & 16.67 & 16.67 & 16.67 & 16.67 & 16.67 & 16.67 & 2.35 & 4.53 & 0.52 \\
\hline Opt. weights_ns & 15.22 & 0.00 & 21.83 & 11.85 & 0.00 & 51.09 & 2.52 & 4.15 & 0.61 \\
\hline 2001-05 until 2010-10 & DIS & UTX & NKE & JNJ & IBM & MCD & & & \\
\hline Ave. $r$ risk adj. & -0.54 & -0.06 & 1.46 & -0.05 & 1.74 & 1.66 & & & \\
\hline Equal weights & 16.67 & 16.67 & 16.67 & 16.67 & 16.67 & 16.67 & 0.70 & 5.46 & 0.13 \\
\hline Opt. weights_ns & 0.00 & 0.00 & 22.56 & 39.82 & 0.00 & 37.63 & 0.93 & 4.62 & 0.20 \\
\hline 2010-11 until 2011-04 & WBA & MSFT & $\mathrm{CSCO}$ & CAT & $\mathrm{V}$ & $\mathrm{BA}$ & & & \\
\hline Ave. $\mathrm{r}$ risk adj. & 16.67 & 16.67 & 16.67 & 16.67 & 16.67 & 16.67 & & & \\
\hline Equal weights & 16.67 & 16.67 & 16.67 & 16.67 & 16.67 & 16.67 & 1.19 & 3.62 & 0.33 \\
\hline Opt. weights_ns & 100.00 & 0.00 & 0.00 & 0.00 & 0.00 & 0.00 & 3.80 & 5.78 & 0.66 \\
\hline 2011-05 until 2011-10 & UTX & PG & AAPL & GS & CAT & MCD & & & \\
\hline Ave. $\mathrm{r}$ risk adj. & -2.32 & -0.17 & 2.21 & -5.46 & -3.41 & 2.87 & & & \\
\hline Equal weights & 16.67 & 16.67 & 16.67 & 16.67 & 16.67 & 16.67 & -1.05 & 5.73 & -0.18 \\
\hline Opt. weights_ns & 27.28 & 0.00 & 30.60 & 0.00 & 16.08 & 26.04 & 0.24 & 4.98 & 0.05 \\
\hline 2011-11 until 2012-04 & CAT & GS & JPM & DIS & TRV & $\mathrm{CSCO}$ & & & \\
\hline Ave. $r$ risk adj. & 1.37 & 0.74 & 3.60 & 3.60 & 1.66 & 1.32 & & & \\
\hline Equal weights & 16.67 & 16.67 & 16.67 & 16.67 & 16.67 & 16.67 & 2.05 & 4.81 & 0.43 \\
\hline Opt. weights_ns & 100.00 & 0.00 & 0.00 & 0.00 & 0.00 & 0.00 & 1.37 & 9.08 & 0.15 \\
\hline 2012-05 until 2012-10 & MRK & JNJ & DIS & WBA & HD & BA & & & \\
\hline Ave. $r$ risk adj. & 2.64 & 1.50 & 1.96 & 0.11 & 2.80 & -1.46 & & & \\
\hline Equal weights & 16.67 & 16.67 & 16.67 & 16.67 & 16.67 & 16.67 & 1.26 & 3.85 & 0.33 \\
\hline Opt. weights_ns & 0.00 & 6.47 & 30.23 & 46.37 & 0.00 & 16.93 & 0.50 & 5.26 & 0.09 \\
\hline 2012-11 until 2013-04 & JPM & $\mathrm{CSCO}$ & GS & CVX & $\mathrm{XOM}$ & WBA & & & \\
\hline Ave. $r$ risk adj. & 2.73 & 3.35 & 2.87 & 1.75 & -0.40 & 5.71 & & & \\
\hline Equal weights & 16.67 & 16.67 & 16.67 & 16.67 & 16.67 & 16.67 & 2.67 & 36.93 & 0.07 \\
\hline Opt. weights_ns & 0.00 & 0.00 & 0.00 & 41.90 & 54.99 & 3.11 & 0.69 & 6.96 & 0.10 \\
\hline $2013-05$ until 2013-10 & PFE & MCD & $\mathrm{XOM}$ & TRV & JNJ & UTX & & & \\
\hline Ave. $\mathrm{r}$ risk adj. & 0.97 & -0.88 & 0.14 & 0.17 & 1.43 & 2.50 & & & \\
\hline Equal weights & 16.67 & 16.67 & 16.67 & 16.67 & 16.67 & 16.67 & 0.72 & 3.56 & 0.20 \\
\hline
\end{tabular}


Ulrich R. Deinwallner., Saudi J Econ Fin, March 2020; 4(3): 115-125

\begin{tabular}{|c|c|c|c|c|c|c|c|c|c|}
\hline Opt. weights_ns & 0.00 & 0.00 & 3.29 & 0.00 & 41.86 & 54.85 & 1.97 & 5.12 & 0.39 \\
\hline 2013-11 until 2014-04 & WBA & GS & UTX & JPM & JNJ & AAPL & & & \\
\hline Ave. $r$ risk adj. & 2.32 & -0.20 & 1.77 & 1.40 & 1.52 & 2.01 & & & \\
\hline Equal weights & 16.67 & 16.67 & 16.67 & 16.67 & 16.67 & 16.67 & 1.47 & 3.31 & 0.44 \\
\hline Opt. weights_ns & 0.00 & 0.00 & 0.00 & 28.29 & 50.59 & 21.12 & 1.59 & 4.05 & 0.39 \\
\hline 2014-05 until 2014-10 & $\mathrm{VZ}$ & UTX & $\mathrm{HD}$ & CAT & MCD & GS & & & \\
\hline Ave. $r$ risk adj. & 1.37 & -1.71 & 3.38 & -0.65 & -1.09 & 2.79 & & & \\
\hline Equal weights & 16.67 & 16.67 & 16.67 & 16.67 & 16.67 & 16.67 & 0.68 & 2.40 & 0.28 \\
\hline Opt. weights_ns & 73.15 & 3.02 & 0.00 & 23.83 & 0.00 & 0.00 & 0.80 & 2.20 & 0.36 \\
\hline 2014-11 until 2015-04 & CAT & HD & TRV & UNH & UTX & KO & & & \\
\hline Ave. $r$ risk adj. & -2.52 & 1.50 & 0.02 & 2.57 & 1.00 & -0.49 & & & \\
\hline Equal weights & 16.67 & 16.67 & 16.67 & 16.67 & 16.67 & 16.67 & 0.35 & 3.03 & 0.11 \\
\hline Opt. weights_ns & 0.00 & 0.00 & 0.00 & 52.85 & 0.00 & 47.15 & 1.13 & 3.25 & 0.35 \\
\hline 2015-05 until 2015-10 & JNJ & MCD & $\mathrm{V}$ & DIS & PFE & PG & & & \\
\hline Ave. $r$ risk adj. & 0.35 & 2.60 & 2.53 & 0.64 & 0.01 & -0.61 & & & \\
\hline Equal weights & 16.67 & 16.67 & 16.67 & 16.67 & 16.67 & 16.67 & 0.92 & 5.22 & 0.18 \\
\hline Opt. weights_ns & 100.00 & 0.00 & 0.00 & 0.00 & 0.00 & 0.00 & 0.35 & 4.37 & 0.08 \\
\hline 2015-11 until 2016-04 & MRK & DIS & MSFT & TRV & BA & CVX & & & \\
\hline Ave. $r$ risk adj. & 0.13 & -1.72 & -0.89 & -0.48 & -1.53 & 2.15 & & & \\
\hline Equal weights & 16.67 & 16.67 & 16.67 & 16.67 & 16.67 & 16.67 & -0.39 & 4.44 & -0.09 \\
\hline Opt. weights_ns & 0.30 & 0.00 & 0.00 & 35.43 & 53.28 & 10.99 & -0.75 & 6.14 & -0.12 \\
\hline 2016-05 until 2016-10 & JNJ & $\mathrm{V}$ & MRK & KO & NKE & DIS & & & \\
\hline Ave. $r$ risk adj. & 0.58 & 0.94 & 1.17 & -0.88 & -2.76 & -1.90 & & & \\
\hline Equal weights & 16.67 & 16.67 & 16.67 & 16.67 & 16.67 & 16.67 & -0.48 & 1.38 & -0.35 \\
\hline Opt. weights_ns & 69.75 & 0.00 & 0.00 & 0.00 & 30.25 & 0.00 & -0.43 & 3.17 & -0.14 \\
\hline 2016-11 until 2017-04 & $\mathrm{HD}$ & PFE & INTC & $\mathrm{CSCO}$ & AAPL & IBM & & & \\
\hline Ave. $r$ risk adj. & 4.06 & 1.22 & 0.61 & 1.79 & 3.84 & 0.74 & & & \\
\hline Equal weights & 16.67 & 16.67 & 16.67 & 16.67 & 16.67 & 16.67 & 2.04 & 2.08 & 0.98 \\
\hline Opt. weights_ns & 0.00 & 0.00 & 0.00 & 7.25 & 9.31 & 83.45 & 1.11 & 4.26 & 0.26 \\
\hline $2017-05$ until 2017-10 & MSFT & HD & UTX & INTC & BA & MCD & & & \\
\hline Ave. $r$ risk adj. & 3.15 & 0.92 & 0.02 & 3.80 & 5.50 & 2.86 & & & \\
\hline Equal weights & 16.67 & 16.67 & 16.67 & 16.67 & 16.67 & 16.67 & 2.71 & 2.24 & 1.21 \\
\hline Opt. weights_ns & 55.37 & 0.00 & 0.00 & 0.00 & 28.11 & 16.52 & 3.76 & 3.05 & 1.23 \\
\hline 2017-11 until 2018-04 & INTC & WMT & $\mathrm{XOM}$ & TRV & $\mathrm{BA}$ & CVX & & & \\
\hline Ave. $r$ risk adj. & 2.00 & 0.09 & -1.15 & -0.24 & 4.14 & 1.28 & & & \\
\hline Equal weights & 16.67 & 16.67 & 16.67 & 16.67 & 16.67 & 16.67 & 1.02 & 4.66 & 0.22 \\
\hline Opt. weights_ns & 0.00 & 20.78 & 0.00 & 31.05 & 0.00 & 48.17 & 0.56 & 5.59 & 0.10 \\
\hline 2018-05 until 2018-10 & NKE & PFE & JNJ & MSFT & JPM & $\mathrm{V}$ & & & \\
\hline Ave. $r$ risk adj. & 1.27 & 2.65 & 1.56 & 1.99 & -0.15 & 1.07 & & & \\
\hline Equal weights & 16.67 & 16.67 & 16.67 & 16.67 & 16.67 & 16.67 & 1.40 & 3.56 & 0.39 \\
\hline Opt. weights_ns & 0.00 & 55.15 & 41.76 & 0.00 & 3.10 & 0.00 & 2.11 & 4.06 & 0.52 \\
\hline 2018-11 until 2019-04 & IBM & CAT & $\mathrm{HD}$ & NKE & AAPL & UTX & & & \\
\hline Ave. $r$ risk adj. & 3.25 & 2.13 & 2.27 & 2.32 & -1.72 & 2.10 & & & \\
\hline Equal weights & 16.67 & 16.67 & 16.67 & 16.67 & 16.67 & 16.67 & 1.73 & 5.03 & 0.34 \\
\hline Opt. weights_ns & 0.00 & 100.00 & 0.00 & 0.00 & 0.00 & 0.00 & 2.13 & 5.63 & 0.38 \\
\hline 2019-05 until 2019-10 & $\mathrm{HD}$ & TRV & PG & WMT & $\mathrm{CSCO}$ & NKE & & & \\
\hline Ave. $r$ risk adj. & 2.19 & -1.74 & 2.45 & 1.97 & -2.90 & 0.03 & & & \\
\hline Equal weights & 16.67 & 16.67 & 16.67 & 16.67 & 16.67 & 16.67 & 0.33 & 4.17 & 0.08 \\
\hline Opt. weights_ns & 0.00 & 0.00 & 58.65 & 25.37 & 0.00 & 15.97 & 1.94 & 3.85 & 0.50 \\
\hline 2019-11 until 2019-12 & CAT & AAPL & INTC & GS & $\mathrm{XOM}$ & NKE & & & \\
\hline Ave. $r$ risk adj. & 3.11 & 7.70 & 2.38 & 3.27 & 1.46 & 5.55 & & & \\
\hline Equal weights & 16.67 & 16.67 & 16.67 & 16.67 & 16.67 & 16.67 & 3.91 & 0.60 & 6.56 \\
\hline Opt. weights_ns & 0.00 & 0.00 & 58.65 & 25.37 & 0.00 & 15.97 & 3.11 & 0.68 & 4.61 \\
\hline
\end{tabular}


Table A-2

\begin{tabular}{|c|c|c|c|c|c|c|c|c|c|}
\hline \multicolumn{4}{|c|}{ MA MOM Yearly Strategy Portfolios } & & & & & & \\
\hline DJIA Stocks & 1 & 2 & 3 & 4 & 5 & 6 & Portfolio & & \\
\hline 2010-04 until 2010-05 & $\overline{B A}$ & $\mathrm{~V}$ & UNH & DIS & AAPL & CAT & $\mathrm{r}$ & STD & SR \\
\hline Ave. r risk adj. & -6.80 & -12.03 & -6.42 & -2.81 & 3.83 & -2.01 & & & \\
\hline Equal weights & 16.67 & 16.67 & 16.67 & 16.67 & 16.67 & 16.67 & -4.37 & 6.29 & -0.69 \\
\hline Opt. weights_ns & 15.12 & 22.56 & 45.84 & 0.00 & 0.00 & 16.48 & -7.01 & 4.04 & -1.74 \\
\hline 2010-07 until 2011-06 & AAPL & BA & MCD & CAT & PFE & PG & & & \\
\hline Ave. $r$ risk adj. & 2.29 & 1.45 & 2.20 & 4.83 & 3.30 & 0.63 & & & \\
\hline Equal weights & 16.67 & 16.67 & 16.67 & 16.67 & 16.67 & 16.67 & 2.45 & 3.37 & 0.73 \\
\hline Opt. weights_ns & 6.62 & 0.00 & 0.00 & 0.00 & 14.81 & 78.57 & 1.14 & 3.21 & 0.35 \\
\hline 2011-07 until 2012-06 & UNH & $\mathrm{V}$ & PFE & IBM & CAT & BA & & & \\
\hline Ave. $r$ risk adj. & 1.05 & 3.35 & 1.16 & 1.13 & -1.84 & 0.14 & & & \\
\hline Equal weights & 16.67 & 16.67 & 16.67 & 16.67 & 16.67 & 16.67 & 0.83 & 4.87 & 0.17 \\
\hline Opt. weights_ns & 0.00 & 52.62 & 22.75 & 24.63 & 0.00 & 0.00 & 2.31 & 3.94 & 0.58 \\
\hline 2012-07 until 2013-06 & AAPL & DIS & $\mathrm{HD}$ & $\mathrm{V}$ & MSFT & WMT & & & \\
\hline Ave. $r$ risk adj. & -3.16 & 2.22 & 3.18 & 3.42 & 1.16 & 0.64 & & & \\
\hline Equal weights & 16.67 & 16.67 & 16.67 & 16.67 & 16.67 & 16.67 & 1.24 & 2.50 & 0.50 \\
\hline Opt. weights_ns & 4.40 & 0.00 & 27.63 & 19.97 & 0.00 & 48.01 & 1.73 & 2.27 & 0.76 \\
\hline 2013-07 until 2014-06 & BA & MSFT & DIS & NKE & HD & $\mathrm{CSCO}$ & & & \\
\hline Ave. $r$ risk adj. & 1.87 & 1.71 & 2.55 & 1.75 & 0.44 & 1.00 & & & \\
\hline Equal weights & 16.67 & 16.67 & 16.67 & 16.67 & 16.67 & 16.67 & 1.55 & 3.27 & 0.47 \\
\hline Opt. weights_ns & 31.75 & 0.00 & 0.00 & 10.24 & 17.32 & 40.68 & 1.25 & 3.93 & 0.32 \\
\hline 2014-07 until 2015-06 & WBA & CAT & INTC & MRK & AAPL & JNJ & & & \\
\hline Ave. $r$ risk adj. & 1.14 & -1.91 & 0.00 & 0.02 & 2.54 & -0.46 & & & \\
\hline Equal weights & 16.67 & 16.67 & 16.67 & 16.67 & 16.67 & 16.67 & 0.22 & 3.02 & 0.07 \\
\hline Opt. weights_ns & 0.00 & 0.00 & 23.45 & 56.66 & 1.47 & 18.42 & -0.04 & 3.44 & -0.01 \\
\hline 2015-07 until 2016-06 & DIS & UNH & AAPL & NKE & WBA & JPM & & & \\
\hline Ave. r risk adj. & -1.30 & 1.25 & -2.21 & 0.17 & -0.08 & -0.60 & & & \\
\hline Equal weights & 16.67 & 16.67 & 16.67 & 16.67 & 16.67 & 16.67 & -0.46 & 4.04 & -0.11 \\
\hline Opt. weights_ns & 0.00 & 0.00 & 40.80 & 59.20 & 0.00 & 0.00 & -0.80 & 4.80 & -0.17 \\
\hline 2016-07 until 2017-06 & $\mathrm{VZ}$ & XOM & WMT & UNH & JNJ & CVX & & & \\
\hline Ave. $r$ risk adj. & -1.63 & -1.08 & 0.40 & 2.27 & 0.81 & 0.16 & & & \\
\hline Equal weights & 16.67 & 16.67 & 16.67 & 16.67 & 16.67 & 16.67 & 0.15 & 2.46 & 0.06 \\
\hline Opt. weights_ns & 0.00 & 60.71 & 39.29 & 0.00 & 0.00 & 0.00 & -0.50 & 2.59 & -0.19 \\
\hline 2017-07 until 2018-06 & BA & MCD & AAPL & $\mathrm{V}$ & CAT & JNJ & & & \\
\hline Ave. $r$ risk adj. & 4.37 & 0.18 & 2.01 & 2.72 & 1.92 & -0.71 & & & \\
\hline Equal weights & 16.67 & 16.67 & 16.67 & 16.67 & 16.67 & 16.67 & 1.75 & 3.15 & 0.56 \\
\hline Opt. weights_ns & 0.00 & 10.37 & 0.00 & 31.32 & 20.26 & 38.05 & 0.99 & 2.78 & 0.36 \\
\hline 2018-07 until 2019-06 & NKE & $\mathrm{V}$ & MSFT & BA & $\mathrm{CSCO}$ & UNH & & & \\
\hline Ave. r risk adj. & 0.26 & 2.02 & 2.40 & 0.56 & 1.96 & -0.22 & & & \\
\hline Equal weights & 16.67 & 16.67 & 16.67 & 16.67 & 16.67 & 16.67 & 1.16 & 5.06 & 0.23 \\
\hline Opt. weights_ns & 33.96 & 32.86 & 0.00 & 0.00 & 33.18 & 0.00 & 1.40 & 5.88 & 0.24 \\
\hline 2019-07 until 2019-12 & MSFT & $\mathrm{V}$ & DIS & $\mathrm{CSCO}$ & AAPL & TRV & & & \\
\hline Ave. $r$ risk adj. & 2.47 & 1.01 & 0.33 & -2.33 & 6.33 & -1.64 & & & \\
\hline Equal weights & 16.67 & 16.67 & 16.67 & 16.67 & 16.67 & 16.67 & 1.03 & 2.59 & 0.40 \\
\hline Opt. weights_ns & 0.00 & 0.00 & 0.00 & 0.00 & 0.00 & 100.00 & -1.64 & 5.13 & -0.32 \\
\hline
\end{tabular}

